\title{
Acute pressure overload of the right ventricle. Comparison of two models of right-left shunt. Pulmonary artery to left atrium and right atrium to left atrium: experimental study
}

Mihalis Argiriou ${ }^{1 *}$, Dimitrios Mikroulis², Timothy Sakellaridis', Vasilios Didilis², Apostolos Papalois ${ }^{3}$ and George Bougioukas ${ }^{2}$

\begin{abstract}
Abtract
Background: In right ventricular failure (RVF), an interatrial shunt can relieve symptoms of severe pulmonary hypertension by reducing right ventricular preload and increasing systemic flow. Using a pig model to determine if a pulmonary artery - left atrium shunt (PA-LA) is better than a right atrial - left atrial shunt (RA-LA), we compared the hemodynamic effects and blood gases between the two shunts.

Methods: Thirty, male Large White pigs weighting in average $21.3 \mathrm{~kg} \pm 0.7$ (SEM) were divided into two groups (15 pigs per group): In group 1, banding of the pulmonary artery and a pulmonary artery to left atrium shunt with an $8 \mathrm{~mm}$ graft (PA-LA) was performed and in group 2 banding of the pulmonary artery and right atrial to left atrial shunt (RA-LA) with a similar graft was performed. Hemodynamic parameters and blood gases were measured from all cardiac chambers in 10 and 20 minutes, half and one hour interval from the baseline (30 min from the banding). Cardiac output and flow of at the left anterior descending artery was also monitored.

Results: In both groups, a stable RVF was generated. The PA-LA shunt compared to the RA-LA shunt has better hemodynamic performance concerning the decreased right ventricle afterload, the 4 fold higher mean pressure of the shunt, the better flow in left anterior descending artery and the decreased systemic vascular resistance. Favorable to the PA-LA shunt is also the tendency - although not statistically significant - in relation to central venous pressure, left atrial filling and cardiac output.
\end{abstract}

Conclusion: The PA-LA shunt can effectively reverse the catastrophic effects of acute RVF offering better hemodynamic characteristics than an interatrial shunt.

Keywords: Right ventricular failure, Right ventricle overload, Pulmonary hypertension, Pulmonary artery banding, Right to left shunt

\section{Background}

Pulmonary hypertension and right ventricular dysfunction are associated with poor survival. Management of patients with acute decompensate RV failure is largely empiric and targeted towards treating underlying precipitants while optimizing conditions of RV preload, afterload and contractility.

\footnotetext{
* Correspondence: mihalisargiriou@ath.forthnet.gr

'Second Cardiac Surgery Department, Evaggelismos General Hospital, 45-47 Ipsilantou, 10676, Athens, Greece

Full list of author information is available at the end of the article
}

However, right-sided heart failure remains a major problem in the long-term follow-up, leading to impairment of functional status, severe arrhythmia, and premature death. Treatment consists of pulmonary vasodilator therapy, long-term oxygen therapy, anticoagulation, and lung transplantation, or, at times, heartlung transplantation. Management strategies for patients who develop acute refractory right ventricular failure are:

1. Mechanical support to the failing right ventricle, 
2. Conventional pulmonary vasodilators,

3. Cavopulmonary diversion in select cases, and

4. Maintenance of an adequate left ventricular performance throughout the recovery period [1].

In recent years, percutaneous balloon atrial septostomy (BAS) has been established as a palliative treatment or bridge to transplantation in patients with severe rightheart failure refractory to conventional therapy [2-5]. BAS aims at creating a "safety valve" by unloading the right heart and increasing left ventricular preload and output, peripheral perfusion, net oxygen tissue delivery, exercise tolerance, and prognosis. However, this procedure is not always successful because the size of the opening made with standard balloon septostomy techniques is imprecise and variable from patient to patient. The mortality rate is relatively high and sometimes related to severe hypoxemia from excessive right-to-left shunting through an overly large defect. Procedural mortality varies widely from 5 to $50 \%$ from single center reports. Beside this procedure has been proposed a "fontanisation" -right ventricular exclusion of the circulation- as a surgical option of RVF [6,7]. Nevertheless the presence of pulmonary hypertension is a contraindication for this procedure. Neither experimental nor clinical data are available regarding the effects of a shunt not at the atrial level but from the pulmonary artery to the left atrium. The purpose of this study was to examine the effects of right ventricle overload of two different shunts in a porcine model.

\section{Materials and methods \\ Surgical Preparation}

The animal research protocol was approved by the local authorities (А.П. 3940/6-10-2008) in Athens. All animals used in this study were treated according to the "Guide for the care and use of Laboratory animals" published by the US National Institutes of Health (National Institutes of Health publication no. 85-23, revised 1996).

Thirty pigs weighing 22 to $35 \mathrm{~kg}$ were premedicated with ketamine hydrochloride (15 mg/kg IM) and midazolam $(0.5 \mathrm{mg} / \mathrm{kg} \mathrm{IM})$, anesthetized with thiopental sodium ( $9 \mathrm{mg} / \mathrm{kg}$ IV bolus) and fentanyl citrate ( $0.5 \mathrm{mg}$ IV bolus), followed by continuous IV infusions of thiopental sodium ( $1 \mathrm{mg} / \mathrm{min})$, fentanyl citrate $(4 \mathrm{mg} / \mathrm{min})$, pancuronium bromide $(0.25 \mathrm{mg} / \mathrm{min})$, and lidocaine $(2 \mathrm{mg} / \mathrm{min})$, throughout the experiment. After intubation $(8 \mathrm{Ch})$, respiration was controlled with a Soxitronic volume respirator (Soxil S.P.A.; Segrate, Italy), supplying oxygen at $100 \%$. No changes of tidal volume, respiratory rate, and percentage of inspired oxygen were made.

The chest was opened via a midline sternotomy, and the heart was suspended in a pericardial cradle. Catheters were placed, in the right atrium via the right external jugular vein which was surgically dissected; a right side arterial line was inserted under direct vision by a small incision in the groin, and in the left atrium directly through the left atrial appendix. To the arterial line was connected a FloTrac sensor also, (Vigileo monitor, Edwards Lifesciences) to measures parameters such as CCO, SVV/SV, SVR. This sensor is achieving measurements by pulse contour analysis based on arterial pressure waveform. In this way it is possible to avoid the use of Swan Ganz and consequently interactions with tricuspid valve function. The proximal to mid left anterior descending (LAD) coronary artery was dissected free and, a transit time flow-meter probe, (Transonic Inc. Ithaca New York 400-Series Multichannel Flowmeter) was applied. The temperature of the animal was kept within $0.5^{\circ} \mathrm{C}$ of the baseline value with a heating blanket and lamp. ECG, for severe rhythm disturbances, arterial pressure, central venous pressure, pulmonary artery pressure and left atrial pressure were continuously monitored. Fluid (Ringers lactate) was given at a rate of $20 \mathrm{ml} / \mathrm{kg}$.

\section{Right ventricular failure model}

To achieve RVF a banding of the very distal main pulmonary artery was performed. For banding we used a vessel loop (nylon tape) with a snare (Figure 1). The banding was persistent until pulmonary artery pressure proximal of the banding was double than pressure distally of the banding. RVF following pulmonary artery banding was defined as a

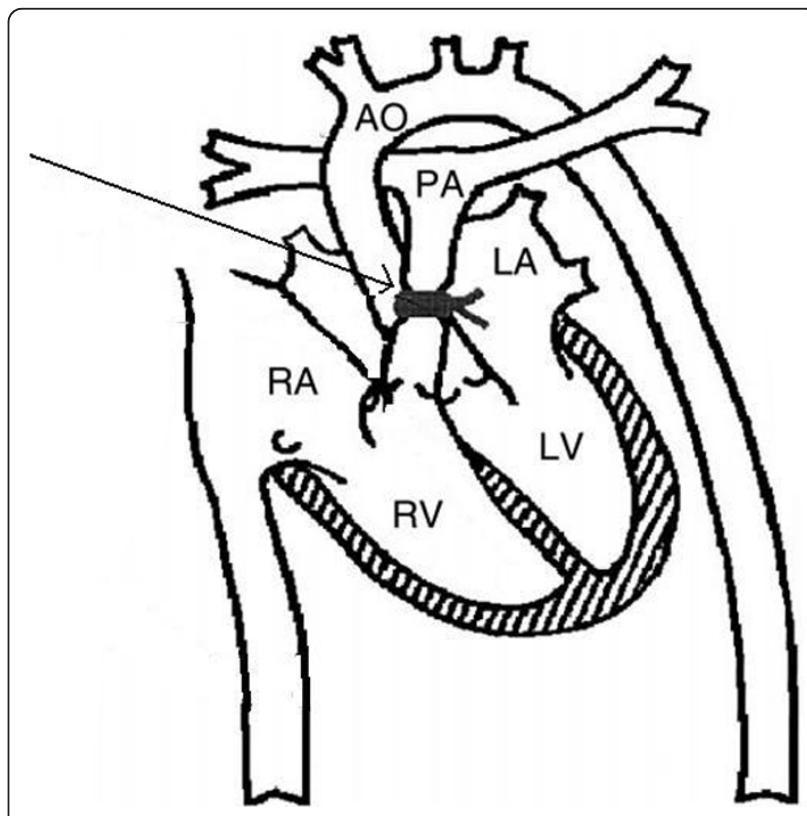

Figure 1 Schematic diagram of the open-chest preparation Note the position of the pulmonary artery (PA) band (arrow). AO = Aorta, $R A=$ right atrium, $L A=$ Left Atrium, RV = Right Ventricle, LV $=$ Left Ventricle. 
profound decrease in systemic blood pressure [mean arterial pressure $(\mathrm{MAP})<2 / 3$ of the beginning], an initial $>1 / 3$ increase of systolic right ventricular pressure (RVP) and a depressed cardiac output ( $<2 / 3$ of the baseline). Additionally, right ventricular function was judged by inspection. After the completion of the banding, 30 min period was allowed for the animal to reach hemodynamic stability before the baseline recordings of pressures, CO, LAD flow and blood gazes measures.

All measurements were taken at end expiration with the ventilator turned off. Pulmonary artery band tightness was adjusted so as not to allow the systolic arterial blood pressure to fall below $60 \mathrm{mmHg}$ at anytime during the experiment. With the beginning of the shunt surgery, the animals were systemically heparinized $(100 \mathrm{U} / \mathrm{kg})$.

\section{Experimental protocol}

Two different settings of shunts were evaluated. Group (1) PA-LA shunt (n 15) and group (2) RA-LA shunt (n 15). A right atrial to the left atrial shunt was created with an interposition of an $8 \mathrm{~mm}$ PTFE graft in group No 2 (Figure 2). By means of partial vascular clamp a PTFE $8 \mathrm{~mm}$ graft was connected end to side with the very proximal main pulmonary artery (proximally of the banding). The other side of the graft was connected end to side with the left auriculum for group No 1 (Figure 3).

We have chosen to introduce the 14-G hypodermic needle into the left atrium, shunt, RV, pulmonary artery proximal and distal directly rather than to introduce a catheter Swan Ganz through the tricuspid valve because of the enhanced stability and reproducibility of the pressure and volumetric data from "a more complete interrogation of the RV cavity". Blood gazes samples from each cavity were selected directly from each cardiac chamber at 10 and 20 minutes from the baseline.

\section{Statistical Analysis}

Data is expressed as mean \pm standard deviation (S.D.) or median (in case of violation of normality) for continuous variables and as percentages for categorical data. The Kolmogorov - Smirnov test was utilized for normality analysis of the parameters. The comparison of variables at each time point was performed using the Independent samples t-test or the Mann-Whitney test in case of violation of normality. One factor Repeated Measures ANOVA model was used for the comparison of different time measurement of variables for each group. Pair wise multiple comparisons were performed using the method of Tukey critical difference.

To indicate the trend in the first 20 minutes of intervention, the median percentage changes after 10 and 20 minutes respectively are calculated. Comparison of percentage change from baseline of parameters during the observation period between two groups was analyzed using the Mann-Whitney test because of violation of normality.

All tests are two-sided, statistical significance was set at $\mathrm{p}<0.05$. All analyses were carried out using the statistical package SPSS ver. 16.00 (Statistical Package for the Social Sciences, SPSS Inc., Chicago, Ill., USA).

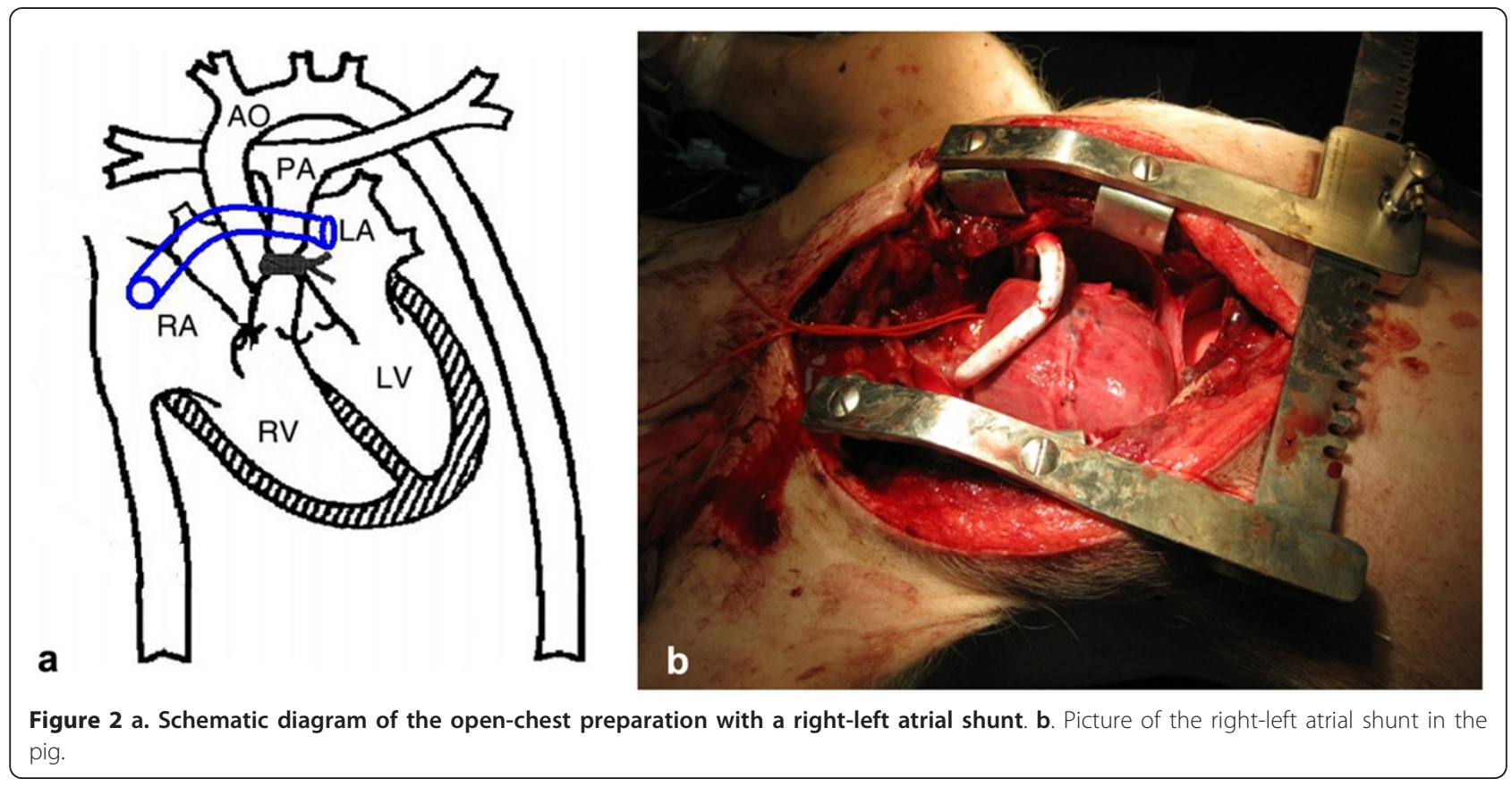




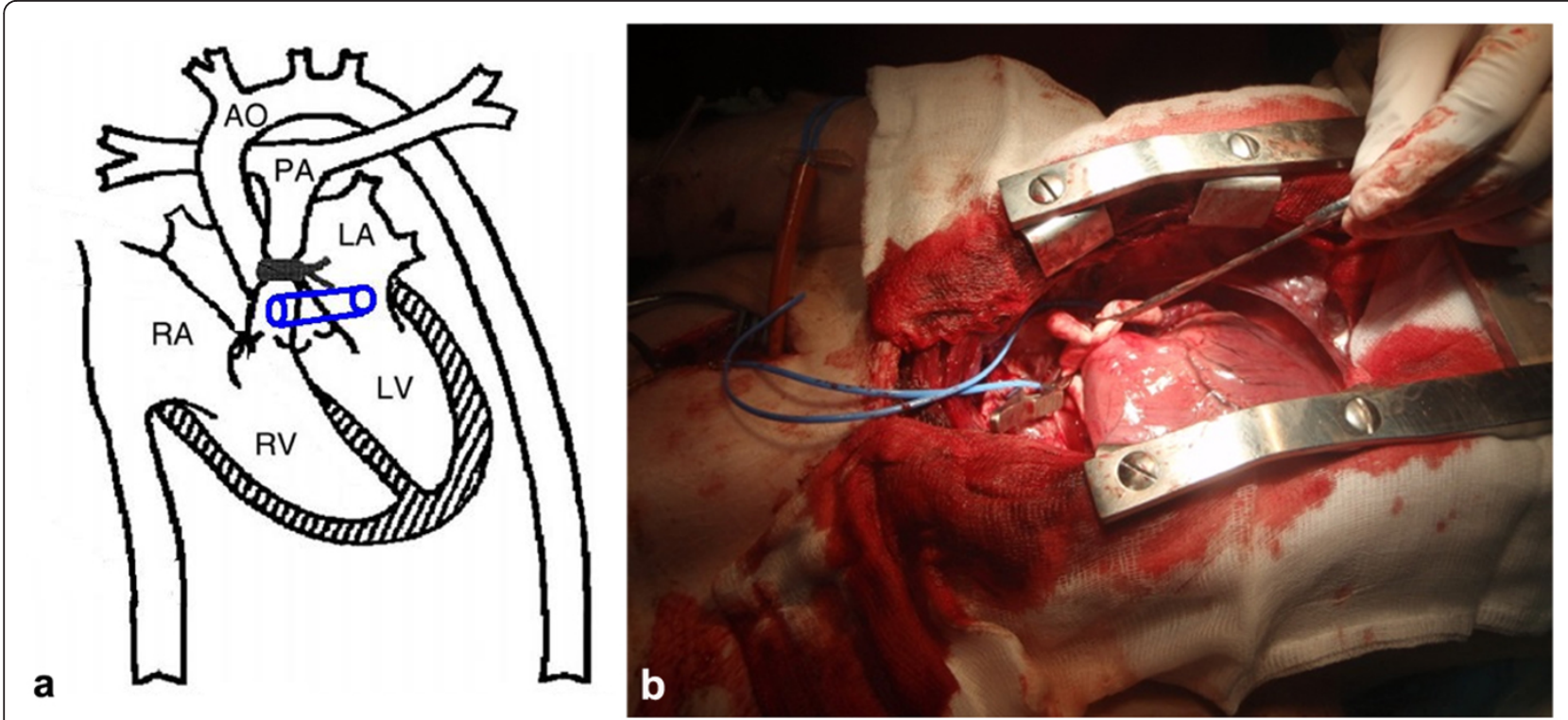

Figure 3 a. Schematic diagram of the open-chest preparation with a pulmonary artery - left atrial shunt. b. Picture of the pulmonary artery -left atrial shunt in the pig.

\section{Results}

\section{Hemodynamics}

The central venous pressure (mean), the mean pressure of left atrium, the cardiac output, the pressure of the distal portion of pulmonary artery at baseline and during 10 and 20 minutes interval were similar in both groups (Table 1).

There is statistically significant difference among the time measurements of heart rate variable for the PA - LA shunt, in comparison with the RA - LA shunt, especially at the 10 minute interval $(\mathrm{p}<0.005)$. Pairwise comparisons show statistically significant difference between all time measurements. The heart rate variable at baseline was $95.5 \pm 10.45$ pulses $/ \mathrm{min}$, at 10 minutes interval with PA - LA shunt was $112.80 \pm 9.71 \mathrm{pulses} / \mathrm{min}$ and at 20 minutes interval $105.20 \pm 16.90$ pulses/min, whereas with the RA - LA shunt the measurements of heart rate variable at 10 and 20 minutes interval were $106.87 \pm$ $18.31 \mathrm{pulses} / \mathrm{min}$ and $103.80 \pm 13.52 \mathrm{pulses} / \mathrm{min}$.

There is statistically significant difference among the time measurements of mean arterial blood pressure variable for the PA - LA shunt, in comparison with the RA LA shunt between al time measurements $(p<0.005)$. The mean blood pressure variable at baseline was $64.67 \pm$ $6.72 \mathrm{mmHg}$, at 10 minutes interval with PA - LA shunt decreased at a variable of $59.33 \pm 14.02 \mathrm{mmHg}$ and at 20 minutes interval at $49.87 \pm 10.08 \mathrm{mmHg}$, whereas with the RA - LA shunt the measurements of mean blood pressure variable at 10 and 20 minutes interval were $59.20 \pm 10.71 \mathrm{mmHg}$ and $58.60 \pm 13.43 \mathrm{mmHg}$. Between the two groups (PA - LA shunt and RA - LA shunt) there is statistically significant difference of mean blood pressure variable at 20 min interval $(p=0,054)$ with the mean blood pressure of PA - LA shunt at the level of $49.87 \pm 10.08 \mathrm{mmHg}$ and of RA - LA shunt at the level of $58.60 \pm 13.43$.

As for the mean right ventricular pressure (RVP) variable, there is statistically significant difference among the time measurements of the RVP variable for the shunt PALA ( $p<0.005)$. Pairwise comparisons show statistically significant difference between all time measurements. Also, between the two groups at 10 minute interval, a significant statistically difference $(\mathrm{p}<0.022)$ is observed with the measurements to be $15.93 \pm 4.73 \mathrm{mmHg}$ for the shunt PA-LA and $10.87 \pm 3.60 \mathrm{mmHg}$ for the shunt RA-LA. Concerning the percentage change from baseline to 10 min of the mean right ventricular pressure variable, there is statistical significant difference between the two groups ( $\mathrm{p}<0.074$ ), with $50 \%$ decrease at the PA-LA shunt and $64 \%$ decrease at the RA-LA shunt.

The variable of shunt pressure has statistically difference between the two groups at 10 minute and 20 minute interval ( $p<0.005)$, whereas there is a significant statistically difference between groups concerning the percentage change from baseline to $20 \mathrm{~min}(\mathrm{p}=0.023)$. Comparison between all time measurements of proximal pulmonary artery pressure for both groups reveals a statistically difference $(\mathrm{p}<0.005)$.

The observed decrease of SVR has a statistically difference among the 20 minute interval measurements for the shunt PA-LA and for the RA-LA shunt ( $<0.005)$. Also there is statistically difference of SVR variable between the two groups at 20 minute interval $(p=0.075)$ and 
Table 1 Hemodynamic measurements and statically analysis

\begin{tabular}{|c|c|c|c|c|c|c|}
\hline & & baseline mean $\pm S D$ & 10 min mean $\pm S D$ & 20 min mean $\pm S D$ & $\%$ change baseline-10 min median & $\%$ change baseline- 20 min median \\
\hline \multirow[t]{3}{*}{ Pulse (b/min) } & Shunt PA -LA & $95.67 \pm 10.45$ & $112.80 \pm 9.71^{* *}$ & $105.20 \pm 16.90$ & 18.75 & 9.28 \\
\hline & Shunt RA -LA & $95.67 \pm 10.45$ & $106.87 \pm 18.31^{*}$ & $103.80 \pm 13.52$ & 8.69 & 9.18 \\
\hline & $\mathrm{p}$-value & NS & NS & NS & NS & NS \\
\hline \multirow[t]{3}{*}{ Arterial Blood pressure (mean) } & Shunt PA -LA & $64.67 \pm 6,72$ & $59.33 \pm 14.02 * *$ & $49.87 \pm 10.08 * *$ & -6.34 & -20.31 \\
\hline & Shunt RA -LA & $64.67 \pm 6,72$ & $59.20 \pm 10.71$ & $58.60 \pm 13.43$ & -7.04 & -14.23 \\
\hline & p-value & NS & NS & 0.054 & NS & NS \\
\hline \multirow[t]{3}{*}{ Right Ventricular pressure (mean) } & Shunt PA -LA & $30.00 \pm 4.42$ & $15.93 \pm 4.73^{* *}$ & $12.53 \pm 4.49^{* *}$ & -50.0 & -60.0 \\
\hline & Shunt RA -LA & $30.00 \pm 4.42$ & $10.87 \pm 3.60^{* *}$ & $13.5 \pm 5.12^{* *}$ & -64.0 & -65.0 \\
\hline & $\mathrm{p}$-value & NS & 0.022 & NS & 0.074 & NS \\
\hline \multirow[t]{3}{*}{ Central Venous pressure (mean) } & Shunt PA -LA & $6.93 \pm 2.40$ & $5.21 \pm 2.99^{*}$ & $5.12 \pm 3.00$ & -25.0 & 0.0 \\
\hline & Shunt RA -LA & $6.93 \pm 2.40$ & $6.53 \pm 2.72^{\$}$ & $3.46 \pm 3.52^{*}$ & 0.0 & -50.0 \\
\hline & p-value & NS & NS & NS & NS & NS \\
\hline \multirow[t]{3}{*}{ Left Atrial pressure (mean) } & Shunt PA -LA & $5.67 \pm 3.29$ & $5.93 \pm 3.51$ & $5.93 \pm 3.10$ & 0.0 & 0.0 \\
\hline & Shunt RA -LA & $5.67 \pm 3.29$ & $4.73 \pm 3.03$ & $4.47 \pm 3.02$ & 0.0 & -18.0 \\
\hline & $\mathrm{p}$-value & NS & NS & NS & NS & NS \\
\hline \multirow[t]{3}{*}{ Pulmonary artery pressure (proximal) } & Shunt PA -LA & $36.73 \pm 5.28$ & $21.73 \pm 8.91^{* *}$ & $21.63 \pm 92.28^{* *}$ & -40.0 & -40.0 \\
\hline & Shunt RA -LA & $36.87 \pm 4.70$ & $29.03 \pm 8.10^{* *}$ & $28.90 \pm 8.10^{* *}$ & -20.0 & -21.0 \\
\hline & $p$-value & NS & NS & NS & NS & NS \\
\hline \multirow[t]{3}{*}{ Pulmonary artery pressure (distal) } & Shunt PA -LA & $12.73 \pm 5.28$ & $12.47 \pm 4.81$ & $12.40 \pm 4.61$ & 0.0 & 0.0 \\
\hline & Shunt RA -LA & $17.13 \pm 5.25$ & $16.80 \pm 4.83$ & $17.27 \pm 5.36$ & 0.0 & 0.0 \\
\hline & $p$-value & NS & NS & NS & NS & NS \\
\hline \multirow[t]{3}{*}{ Shunt pressure } & Shunt PA -LA & & $19.60 \pm 4.94$ & $19.93 \pm 4.83$ & & -5.0 \\
\hline & Shunt RA -LA & & $5.53 \pm 1.40$ & $4.87 \pm 1.36$ & & -14.3 \\
\hline & $p$-value & & $\mathrm{p}<0,0005$ & $p<0,0005$ & & 0.023 \\
\hline \multirow[t]{3}{*}{ CO } & Shunt PA -LA & $4.93 \pm 0.90$ & $5.19 \pm 1.22$ & $5.39 \pm 1.34$ & 3.92 & 14.03 \\
\hline & Shunt RA -LA & $4.93 \pm 0.90$ & $4.64 \pm 1.02$ & $4.87 \pm 1.13$ & -7.69 & -2.33 \\
\hline & $p$-value & NS & NS & NS & NS & NS \\
\hline \multirow[t]{3}{*}{$S V R$} & Shunt PA -LA & $962.02 \pm 153.04$ & $847.17 \pm 207.17^{* 5}$ & $667.97 \pm 207.64^{* *}$ & -15.44 & -29.90 \\
\hline & Shunt RA -LA & $962.02 \pm 153.04$ & $891.98 \pm 221.52$ & $815.47 \pm 213.14^{* *}$ & -6.20 & -14.81 \\
\hline & $p$-value & NS & NS & 0.075 & NS & 0.021 \\
\hline \multirow[t]{3}{*}{ Flow LAD } & Shunt PA -LA & $18.43 \pm 6.83$ & $16.14 \pm 4.28$ & $20.93 \pm 7.35$ & -8.3 & 9.1 \\
\hline & Shunt RA -LA & $18.43 \pm 6.83$ & $14.64 \pm 5.37^{*}$ & $10.79 \pm 4.98^{* *}$ & -28.0 & -33.3 \\
\hline & p-value & NS & NS & $\mathrm{p}<0,0005$ & NS & $p<0,0005$ \\
\hline
\end{tabular}

** $p<0.005$ vs. baseline, ${ }^{*} p<0.05$ vs. baseline, $\$ p<0.05$ vs. 20 min 
there is statistical significant difference between the two groups concerning the percentage change from baseline to 20 minutes of the SVR variable $(p=0.021)$.

Another important variable that was measured was the flow at the LAD. Measurements revealed statistically significant difference among the time measurements of the LAD flow variable for the shunt RA-LA $(\mathrm{p}<0.005)$ at 20 minute interval, with a $33.3 \%$ decrease. Between the two groups, at 20 minutes interval, the observed difference is statistically significant $(\mathrm{p}<0.005)$. Finally, the observed LAD flow variable between the two groups at 20 minutes has a significant statistically difference $(\mathrm{p}<0.005)$.

\section{Blood gases}

The statistical analysis of blood gases in both groups of shunt and at all time intervals revealed no statistically difference for arterial $\mathrm{pCO}_{2}$ and arterial $\mathrm{pO}_{2}$, arterial $\mathrm{O}_{2} \%$ saturation, pulmonary artery $\mathrm{pH}, \mathrm{pCO}_{2}$ of pulmonary artery and $\mathrm{O}_{2} \%$ saturation of left atrium (Table 2).

The decrease of $\mathrm{pO}_{2}$ in the pulmonary artery is statistically significant among the time measurements of the $\mathrm{pO}_{2}$ variable for the shunt PA-LA ( $\mathrm{p}<0.005)$. Pairwise comparisons show statistically significant difference between all time measurements. The same observations are made for the decrease of $\mathrm{O}_{2} \%$ saturation of the pulmonary artery.

$\mathrm{pCO}_{2}$ of the left atrium increase is statistically significant between the two groups at 10 minute interval $(p=0.052)$ and at 20 minute interval ( $\mathrm{p}=0.058$ ). There is also a statistical significant difference between groups concerning the percentage change from baseline to 10 minute of the $\mathrm{pCO}_{2}$ of the left atrium variable $(\mathrm{p}=0.016)$ and the percentage change from baseline to 20 minute of the $\mathrm{pCO}_{2}$ of the left atrium variable $(\mathrm{p}=0.023)$.

Least, the $\mathrm{pO}_{2}$ of the left atrium decrease reveals a statistically significant difference among the time measurements for the shunt PA-LA $(\mathrm{p}<0.005)$ and RA-LA shunt. Pairwise comparisons show statistically significant difference between all time measurements. At 10 minute interval, between the two groups there is a statistically difference $(\mathrm{p}=0.015)$, and concerning the percentage change from baseline to 10 minute, the difference between the two groups is statistical significant $(\mathrm{p}=0.05)$.

It is anticipated that the minor fall of PO2 and the minor increase of $\mathrm{PCO} 2$ will not influence saturation because of the morphology of the oxygen-hemoglobulin dissociation curve. The discrepancy between arterial $\mathrm{pO}_{2}$, $\mathrm{pCO}_{2}$ and left atrial $\mathrm{pO}_{2}, \mathrm{pCO}_{2}$ can be interpreted as a technical error or as a condition error, probably because of contiguity of the sample collector to the graft.

\section{Discussion}

Right ventricular function is identified to be an independent risk factor for mortality in various diseases as chronic obstructive pulmonary disease (COPD), pulmonary arterial hypertension (PAH) (RV failure is the end-result of PAH and the cause of at least $70 \%$ of all PAH deaths), adult respiratory distress syndrome (ARDS), etc [8]. Also pulmonary hypertension secondary to dilated cardiomyopathy constitutes a risk factor for heart transplantation procedure because of the dysfunction of the right ventricle of the graft [9]. Dysfunction of the right ventricle (RV) can occur in a number of clinical scenarios, including pressure overload, cardiomyopathies, ischemic, congenital, or valvular heart disease, arrhythmias, and sepsis. Pressure overload can occur in an acute or chronic setting [10].

Often the development of a RVF exhibits the final phase of the disease. In cardiothoracic surgery, RVF seems to be a frequent cause for postoperative cardiogenic shock associated with high mortality [11-13]. Different surgical techniques has been proposed for RVF, as atrial septostomy [3], extracorporeal right to left atrial bypass with a centrifuge blood pump and a membrane oxygenator [14], an experimental atrial septostomy with veno-venous extracorporeal membrane oxygenation (VV-ECMO) [15], or a creation of a peripheral shunt [16]. Nevertheless, the implantation of a right side assist device is associated with a high mortality [17].

The first idea of a pulmonary artery to left atrium shunt was introduced 50 years ago, and belongs to Bilgutay and Lillehei [18]. Gupta evaluate in 1972 a PA-left atrium shunt in pulmonary hypertension in an experimental model [19]. The most important side effect of Gupta's model, but also in recent practice of atrial septostomy, is severe hypoxemia from excessive right-to-left shunting. Our recordings confirmed the decrease of arterial oxygen in both groups, but it was not statistical significant (Figure 4).

Besides several other mechanisms which lead to low cardiac output in RVF, a major feature is a reduced trans-pulmonary blood flow with a reduced left atrial respectively ventricular filling result, which is called serial ventricular interdependence. Our aim was to evaluate hemodynamic status of a pulmonary artery to left atrium shunt which can have many advantages and comparison of this shunt with an interatrial shunt.

Pulmonary artery banding in pigs reproducibly results in right side circulatory failure detectable as an increase in right ventricular and mean pulmonary artery pressures and a decrease in left ventricular end-diastolic pressure. In our study, in both groups after shunting it was detectable an increase in heart rate at 10 and 20 minute and a decrease of mean arterial pressure but there was statistically significant difference of mean arterial pressure between the two groups at 20 minute $(p=0.054)$ being more prominent in group 1 (PA-LA) shunt. This result can be explained from the concomitant decrease in this 
Table 2 Blood gases and statistically analysis.

\begin{tabular}{|c|c|c|c|c|c|c|}
\hline & & baseline mean $\pm S D$ & 10 min mean $\pm S D$ & 20 min mean $\pm S D$ & $\%$ change baseline-10 min median & $\%$ change baseline-20 min median \\
\hline \multirow[t]{3}{*}{$p \mathrm{CO}_{2}$ arterial } & Shunt PA -LA & $32.98 \pm 7.61$ & $33.23 \pm 6.06$ & $34.25 \pm 6.84$ & 0.0 & 5.1 \\
\hline & Shunt RA -LA & $32.98 \pm 7.61$ & $31.28 \pm 7.07$ & $32.65 \pm 6.20$ & $-1,39$ & 0.30 \\
\hline & $p$-value & NS & NS & NS & NS & NS \\
\hline \multirow[t]{3}{*}{$\mathrm{pO}_{2}$ arterial } & Shunt PA -LA & $377.02 \pm 82.72$ & $352.31 \pm 76.01$ & $335.65 \pm 55.35^{*}$ & -5.18 & -8.78 \\
\hline & Shunt RA -LA & $377.02 \pm 82.72$ & $362.27 \pm 90.92$ & $362.86 \pm 90.10$ & 0.0 & 0.0 \\
\hline & p-value & NS & NS & NS & NS & NS \\
\hline \multirow[t]{3}{*}{$\mathrm{O}_{2}$ Sat arterial } & Shunt PA -LA & $99.45 \pm 0.94$ & $99.24 \pm 0.95$ & $99.32 \pm 0.88$ & -0.10 & 0.0 \\
\hline & Shunt RA -LA & $99.45 \pm 0.94$ & $99.43 \pm 0.90$ & $99.59 \pm 0.58$ & 0.0 & 0.0 \\
\hline & $\mathrm{p}$-value & NS & NS & NS & NS & NS \\
\hline \multirow[t]{3}{*}{ pH pulmonary artery (distal) } & Shunt PA -LA & $7.50 \pm 0.09$ & $7.44 \pm 0.07$ & $7.44 \pm 0.08$ & -0.27 & -0.66 \\
\hline & Shunt RA -LA & $7.50 \pm 0.09$ & $7.44 \pm 0.06$ & $7.42 \pm 0.07$ & -0.27 & -0.94 \\
\hline & $p$-value & NS & NS & NS & NS & NS \\
\hline \multirow[t]{3}{*}{$p \mathrm{CO}_{2}$ pulmonary artery (distal) } & Shunt PA -LA & $36.54 \pm 8.25$ & $43.22 \pm 7.19^{*}$ & $42.78 \pm 8.26^{*}$ & 11.11 & 11.11 \\
\hline & Shunt RA -LA & $36.54 \pm 8.25$ & $40.13 \pm 8.40$ & $41.25 \pm 7.61^{*}$ & 4.06 & 10.62 \\
\hline & $p$-value & NS & NS & NS & NS & NS \\
\hline \multirow[t]{3}{*}{$\mathrm{pO}_{2}$ pulmonary artery (distal) } & Shunt PA -LA & $39.66 \pm 6.40$ & $33.40 \pm 5.11^{* *}$ & $33.19 \pm 6.22^{* *}$ & -9.97 & -14.65 \\
\hline & Shunt RA -LA & $39.66 \pm 6.40$ & $33.48 \pm 4.44^{* *}$ & $35.66 \pm 6.31^{*}$ & -15.21 & -5.47 \\
\hline & $p$-value & NS & NS & NS & NS & NS \\
\hline \multirow[t]{3}{*}{$\mathrm{O}_{2}$ Sat pulmonary artery (distal) } & Shunt PA -LA & $76.86 \pm 9.63$ & $65.58 \pm 9.69 * *$ & $64.98 \pm 10.75^{* *}$ & -14.74 & -14.28 \\
\hline & Shunt RA -LA & $76.86 \pm 9.63$ & $64.75 \pm 8.78^{* *}$ & $65.83 \pm 12.19^{*}$ & -16.86 & -7.39 \\
\hline & $p$-value & NS & NS & NS & NS & NS \\
\hline \multirow[t]{3}{*}{ pCO2 left atrium } & Shunt PA -LA & $36.10 \pm 4.07$ & $40.68 \pm 4.31^{* *}$ & $39.54 \pm 5.15^{*}$ & 10.40 & 3.32 \\
\hline & Shunt RA -LA & $36.10 \pm 4.07$ & $37.30 \pm 4.80$ & $35.84 \pm 5.11$ & 1.07 & -6.63 \\
\hline & $p$-value & NS & 0.052 & 0.058 & 0.016 & 0.023 \\
\hline \multirow[t]{3}{*}{ pO2 left atrium } & Shunt PA -LA & $172.85 \pm 43.10$ & $99.27 \pm 19.83^{* *}$ & $118.23 \pm 24.57^{* *}$ & -42.05 & -25.50 \\
\hline & Shunt RA -LA & $172.85 \pm 43.10$ & $114.47 \pm 10.96^{* *}$ & $121.30 \pm 17.01^{* *}$ & -36.57 & -29.94 \\
\hline & $p$-value & NS & 0.015 & NS & 0.050 & NS \\
\hline \multirow[t]{3}{*}{$\mathrm{O}_{2}$ Sat left atrium } & Shunt PA -LA & $99.10 \pm 0.97$ & $97.01 \pm 2.20^{*}$ & $97.74 \pm 1.88$ & -2.61 & -1.00 \\
\hline & Shunt RA -LA & $99.10 \pm 0.97$ & $97.46 \pm 2.65$ & $98.71 \pm 0.89$ & -0.51 & -0.31 \\
\hline & p-value & NS & NS & NS & NS & NS \\
\hline
\end{tabular}

** $p<0.005$ vs. baseline, ${ }^{*} p<0.05$ vs. baseline, $\$ p<0.05$ vs. 20 min 
Correlation of percentage change from the baseline of $\mathrm{pO}_{2}$ arterial between the two shunts

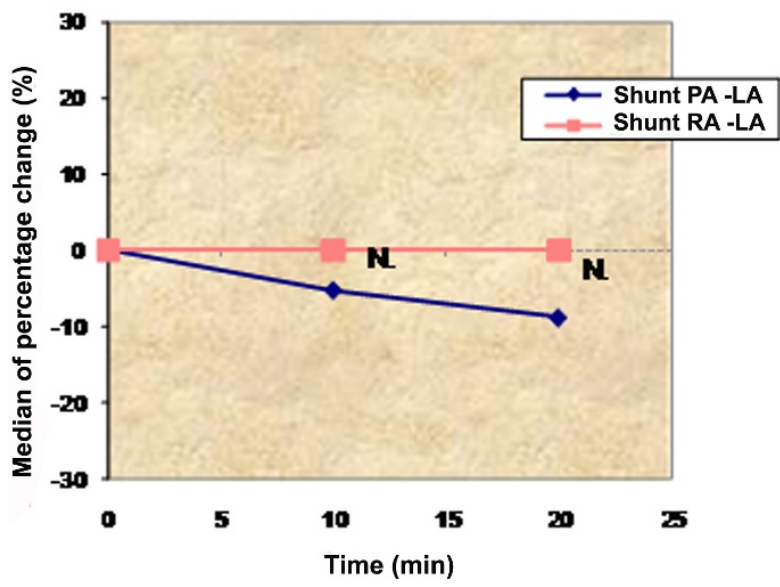

Figure 4 Correlation of percentage change from the baseline of $\mathrm{pO}_{2}$ arterial between the two shunts.

group of SVR at 20 minutes. There is statistical significant difference between groups concerning the percentage change from baseline to 10 minute of the SVR variable and a statistically significant difference between the two groups at 20 minute $(\mathrm{p}=0.075)$. Our recordings of a low MAP and low SVR in both groups are consistent with the results described by other investigators [20-22].

The right ventricular pressure was statistically significant higher in the group of RA-LA. Right ventricular overload - pressure lead often to life threatening ventricular tachycardias. From this point of view the PA-LA shunt has a significant advantage. We observed that right atrial pressure in both groups was not increased as expected, because the experiment was acute and the tricuspid valve by epicardial echocardiography had sufficient competence. However, an interatrial shunt is likely beneficial only if sufficient right-to-left shunting occurs to increase cardiac output.

The results of lower mean arterial pressure and SVR in favor of PA-LA shunt insinuate easier manipulation of heart function in order to optimize heart performance by simple maneuvers like volume infusion or medical intervention in cases of real conditions of right ventricle overload.

Atrial septostomy has been associated with a risk of intraprocedural and postprocedural mortality up to $30 \%$ in several series [3,5,23-25], most commonly, secondary to progressive hypoxia, right heart failure and ventricular arrhythmias. For this reason, Zierer et al [26] had tried to determine the qualitative and quantitative impact of low-flow vs. high-flow shunting. In this study, low-flow shunting (15\% of cardiac output) improved RV diastolic compliance by $42 \%$ and caused a shift of the
RA reservoir-to-conduit ratio toward physiological conditions. In our study, the cardiac output was not significantly different between the two groups. This can be attributed to the Frank-Starling mechanism. According to the Frank-Starling mechanism, as the heart is stretched in response to increased preload, it augments its contraction force at the expense of increased myocardial oxygen consumption. But in our study we observed that flow in LAD had statistically significant difference between the groups concerning the percentage change from baseline to 10 minutes and statistically significant difference between the two groups at 20 minutes ( $\mathrm{p}<$ 0.0005) in favor of the PA-LA shunt (Figure 5, 6).

According the Hagen-Poiseuille law

$$
Q=\frac{\pi}{8 \eta} \frac{P i-P o}{L} R^{4}
$$

the PA - LA shunt has 10 fold higher volumetric flow rate, where $Q$ : volumetric flow rate, $\pi$ : mathematical constant, $\eta$ : dynamic fluid viscosity [pascal - second $(\mathrm{Pa} \cdot \mathrm{s})], P_{i}$ : inlet pressure, $P_{o}$ : outlet pressure, $L$ : total length of the tube in the $x$ direction (meters), $R$ : is the radius.

Because of the anatomical contiguity between pulmonary artery and left atrium, the length of the PA-LA graft is always shorter than the RA-LA graft. The pressure gradient PA-LA is always higher than the RA-LA. These two issues constitute an inherent advantage of PA-LA shunt and are rendering PA-LA shunt more effectively in that it can provide wider range of achievable flows through the shunt. Given the fact that the current technology allows the pulmonary artery banding to be adjustable, we can assume that in the future we may be able to calculate the ideal flow in an individualized manner.

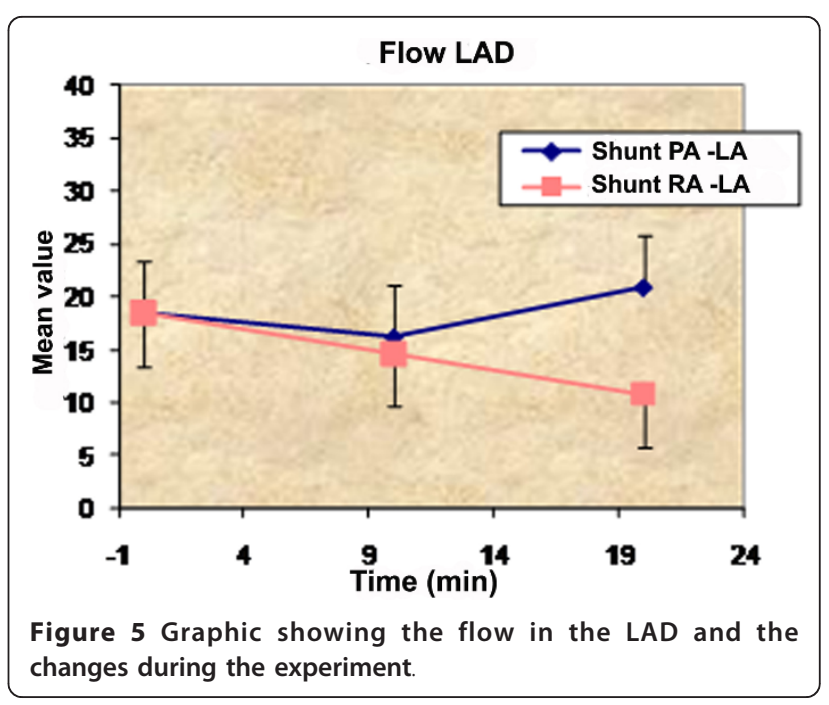




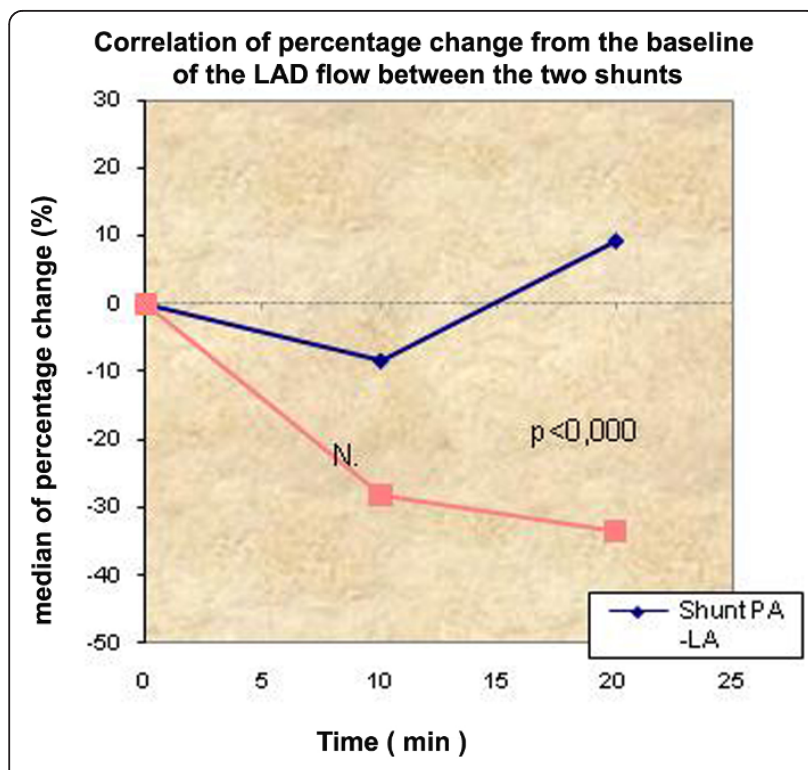

Figure 6 Correlation of percentage change from the baseline of the LAD between the two shunts.

To our surprise, systemic arterial de-saturation following the PA-LA shunt was not increased dramatically with devastating consequences such as systemic oxygen delivery. The advantages of a pulmonary artery to left atrium shunt are the following:

1. Can be performed without extracorporeal circulation

2. Can be used with a telemetrically controlled adjustable occlusion device, as the Flo-Watch pulmonary artery banding device (EndoArt, Lausanne, Switzerland), which has been successfully introduced in clinical practice of banding [20].

3. Can be easily occluded with the current devices, as the Gianturco-Grifka vascular occlusion device which is an appropriate closure system to occlude the shunt because of the large size $(9 \mathrm{~mm})$ [21]

4. Can be easily performed in conjunction with a pumpless lung assist device as Novalung in parallel with the PA shunt or in a serial setting [22].

\section{Conclusion}

Our experiments have showed that a PA-LA shunt can more effectively moderate or even partially reverse the adverse effects of acute right ventricle pressure overload than an interatrial shunt, offering a decrease in right ventricle afterload, increased flow in left anterior descending artery with less mean arterial pressure and lower SVR.

\section{Limitations}

Our study has some limitations. First of all, all measurements were performed in open chest surgery. Secondly, the ventilation supplying oxygen was at $100 \%$ and not at room air oxygen. Finally the measurements were taken at 10 and 20 minute interval. The above parameters may alter the results of blood gases. Nevertheless all measurements taken together allow for a realistic evaluation of the overall picture. The use of other acute RVF models and the determination of long term results are a matter of further investigations.

\section{Abbreviations}

RV: Right Ventricle; RA: Right Atrium; RVF: Right ventricular failure; RVO: Right ventricular overload; PA-LA: pulmonary artery to left atrium shunt; RA-LA: Right atrium to left atrium shunt; LAD: left anterior descending artery; CCO: Continuous Cardiac Output; SV: Stroke Volume; SW: Stroke Volume Variation; SVR: Systemic Vascular Resistance; COPD: chronic obstructive pulmonary disease; PAH: pulmonary arterial hypertension; ARDS: adult respiratory distress syndrome; ECG: Electrocardiogram; RVP: Right Ventricular Pressure.

\section{Author details}

${ }^{1}$ Second Cardiac Surgery Department, Evaggelismos General Hospital, 45-47 Ipsilantou, 10676, Athens, Greece. ${ }^{2}$ Cardiothoracic Surgery Department, Democritus University Thrace, University Hospital of Alexandroupolis, Dragana, 68100, Greece. ${ }^{3}$ Surgical Experimental Laboratories ELPEN (AP), 95 Marathonos Avenue, 19009, Pikermi, Athens, Greece.

\section{Authors' contributions}

All authors read and approved the final manuscript.

MA and TS performed all the experiments, collected the data and drafted the manuscript.

AP is the clinical director of the experimental laboratory, helped out with the experiments and the data collection.

DM revised it critically for important intellectual content

VD revised it critically for important intellectual content

GB have given final approval of the version to be published

\section{Competing interests - Disclosures}

The authors declare that they have no competing interests.

Received: 7 September 2011 Accepted: 19 October 2011

Published: 19 October 2011

\section{References}

1. Oz MC, Slater JP, Edwards N, et al: Desaturated venous to arterial shunting reduces right-sided heart failure after cardiopulmonary bypass. Journal of Heart and Lung Transplants 1995, 14:172-176.

2. Badesch DB, Abman SH, Simonneau G, et al: Medical therapy for pulmonary arterial hypertension: updated ACCP evidence-based clinical practice guidelines. Chest 2007, 131:1918-1928.

3. Reichenberger F, Pepke-Zaba J, McNeil K, et al: Atrial septostomy in the treatment of severe pulmonary arterial hypertension. Thorax 2003, 58:797-800.

4. Law M, Grifka RG, Mullins CE, Nihill MR: Atrial septostomy improves survival in select patients with pulmonary hypertension. Am Heart J 2007, 153(5):779-784.

5. Kurzyna M, Dabrowski M, Bielecki D, et al: Atrial septostomy in treatment of end-stage right heart failure in patients with pulmonary hypertension. Chest 2007, 131(4):977-983.

6. Takagaki M, Ishino K, Kawada M, Ohtsuki S, Hirota M, Tedoriya T, Tanabe Y, Nakai M, Sano S: Total right ventricular exclusion improves left ventricular function in patients with end-stage congestive right ventricular failure. Circulation 2003, 108(Suppl 1):II226-9.

7. Kaul TK, Kahn DR: Postinfarct refractory right ventricle: right ventricular exclusion. A possible option to mechanical cardiac support, in patients unsuitable for heart transplant. J Cardiovasc Surg (Torino) 2000, 41(3):349-355.

8. D'Alonzo GE, Barst RJ, Ayres SM, et al: Survival in patients with primary pulmonary hypertension: results from a national prospective registry. Annals of Internal Medicine 1991, 115(5):343-349. 
9. Bourge RC, Kirklin JK, Naftal DC, et al: Analysis and predictors of pulmonary vascular resistance after cardiac transplantation. J Thorac Cardiovasc Surg 1991, 101:432-435.

10. Simon MA, Pinsky MR: Right ventricular dysfunction and failure in chronic pressure overload. Cardiol Res Pract 2011, 2011:568095.

11. Dávila-Román VG, Waggoner AD, Hopkins WE, Barzilai B: Right ventricular dysfunction in low output syndrome after cardiac operations: assessment by transesophageal echocardiography. Ann Thorac Surg 1995, 60(4):1081-1086

12. Haddad F, Couture P, Tousignant C, Denault AY: The right ventricle in cardiac surgery, a perioperative perspective: II. Pathophysiology, clinical importance, and management. Anesth Analg 2009, 108(2):422-433.

13. Haddad F, Couture P, Tousignant C, Denault AY: The right ventricle in cardiac surgery, a perioperative perspective: I. Anatomy, physiology, and assessment. Anesth Analg 2009, 108(2):407-421.

14. Arpesella G, Mikus E, Loforte A, Mikus PM: Right-left atrium by-pass as salvage treatment for graft failure after heart transplantation. Eur J Cardiothorac Surg 2007, 32(4):671-673.

15. Camboni D, Akay B, Sassalos P, Toomasian JM, Haft JW, Bartlett RH, Cook KE: Use of venovenous extracorporeal membrane oxygenation and an atrial septostomy for pulmonary and right ventricular failure. Ann Thorac Surg 2011, 91(1):144-149.

16. Slater JP, Goldstein DJ, Ashton RC Jr, Levin HR, Spotnitz HM, Oz MC: Rightto-left veno-arterial shunting for right-sided circulatory failure. Ann Thorac Surg 1995, 60(4):978-984.

17. Craig ML: Management of right ventricular failure in the era of ventricular assist device therapy. Curr Heart Fail Rep 2011, 8(1):65-71

18. Bilgutay AM, Sanchez LH, Siegal DL, Lillehei CW: Effect of pulmonary artery-left atrium shunts on ischemic hearts-experimental study and clinical application. Surg Forum 1961, 12:229-232.

19. Gupta S: Role of pulmonary arterial-left atrial shunt in the treatment of pulmonary hypertension. Experimental study. I Thorac Cardiovasc Surg 1972, 64(6):949-952.

20. Corno AF, Ladusans EJ, Pozzi M, Kerr S: FloWatch versus conventional pulmonary artery banding. J Thorac Cardiovasc Surg 2007, 134(6):1413-1419.

21. Zanchetta M, Rigatelli G, Pedon L, Zennaro M, Maiolino P, Onorato E: Transcatheter amplatzer duct occluder closure of direct right pulmonary artery-to-left atrium communication. Cath Cardiovasc Interven 2003, 58:107-110.

22. Spillner J, Amerini A, Hatam N, Rex S, Pott F, Goetzenich A, Menon A, Repas T, Steiner F, Autschbach R, Carpi A, Oster O: Pulmono-atrial shunt and lung assist to treat right ventricular failure. Front Biosci 2011, 17:2342-2351

23. Kerstein D, Levy PS, Hsu DT, Hordof AJ, Gersony WM, Barst RJ: Blade balloon atrial septostomy in patients with severe primary pulmonary hypertension. Circulation 1995, 91:2028-2035.

24. Rich S, Dodin E, McLaughlin W: Usefulness of atrial septostomy as a treatment for primary pulmonary hypertension and guidelines for its application. Am J Cardiol 1997, 80:369-371.

25. Thanopoulos BD, Georgakopoulos D, Tsaousis GS, Simeunovic S: Percutaneous balloon dilatation of the atrial septum: immediate and midterm results. Heart 1996, 76:502-506.

26. Zierer A, Melby SJ, Voeller RK, Moon MR: Interatrial shunt for chronic pulmonary hypertension: differential impact of low-flow vs. high-flow shunting. Am J Physiol Heart Circ Physiol 2009, 296(3):H639-644.

doi:10.1186/1749-8090-6-143

Cite this article as: Argiriou et al: Acute pressure overload of the right ventricle. Comparison of two models of right-left shunt. Pulmonary artery to left atrium and right atrium to left atrium: experimental study. Journal of Cardiothoracic Surgery 2011 6:143.

\section{Submit your next manuscript to BioMed Central and take full advantage of:}

- Convenient online submission

- Thorough peer review

- No space constraints or color figure charges

- Immediate publication on acceptance

- Inclusion in PubMed, CAS, Scopus and Google Scholar

- Research which is freely available for redistribution

Submit your manuscript at www.biomedcentral.com/submit
C Biomed Central 